\title{
Online Public Participation Geographic Information System (PPGIS) as a landscape and public use management tool: a case study from the Ebro Delta Natural Park (Spain)
}

\begin{abstract}
This paper presents a Public Participation Geographic Information System (PPGIS) application conducted in the Ebro Delta Natural Park, Spain. It aims to support decision-making and management activities. The application is based on an online PPGIS questionnaire using Google Maps API. Participants were asked about the spatial and temporal usage while visiting the Natural Park, about their landscape preferences, and appreciations. A set of eight pairs of bipolar adjectives related to landscape characteristics and experience, four items related to public use, and nine to leisure activities were used. In total, 204 valid answers and 3,969 georeferenced opinions were mapped by this case study. The results of this mapping give insights in the use, perception and appreciation of landscape naturalness and aesthetic beauty, accessibility, facilities, services, and signposting. Furthermore, this study discuss the outcomes of mapping the results and how they support the park management with regard to the identification of conflicts, and the need for action. Finally, this study discuss potentials and limitations of PPGIS as a tool for public participation to capture visitors' experiential knowledge in order to optimize and enhance the management of protected areas.
\end{abstract}

\author{
Amalia Vaneska Palacio Buendía \\ ${ }^{1}$, Yolanda Pérez-Albert ${ }^{2}$, David \\ Serrano Giné 3* $^{*}$ \\ 1) Universidad Internacional de La \\ Rioja, La Rioja, Spain \\ 2) Universitat Rovira i Virgili, Vila- \\ seca, Spain \\ 3) Universidad Nacional de Educación \\ a Distancia, Barcelona, Spain \\ *Corresponding author: David \\ Serrano Giné, Universidad Nacional \\ de Educación a Distancia, av/Rio de \\ Janeiro, 56-58, 08016, Barcelona, \\ Spain, Email: dserrano@terrassa. \\ uned.es
}

\section{Keywords:}

Public Participation Geographic Information Systems, Google Maps, park experience, decision support, landscape values mapping 


\section{Landscape perception and public use as social demands in protected areas management}

Management in protected areas has to provide solutions for a variety of demands and goals, and undertake a wide array of measures related to the reason why sites are designated (Lausche 2011). Many designations have been conceived under conservation and biodiversity criteria, and their main aim is to preserve and promote ecological processes or biophysical elements (Plieninger et al. 2013). However, some protected areas also have the statutory mandate to provide for public use, which in some cases may come into conflict with conservation objectives or biophysically-driven management criteria (Hornback and Eagles 1999, Blicharska et al. 2016). Public use embraces tourism, visitation, education, recreation, and other visitor-related activities, and it is a crucial issue in many protected areas (Eagles et al. 2002, Leung et al. 2018). EUROPARC (2005) pinpoints five items relevant in public use: administrative management, facilities and amenities, visitor programmes, and visitors and activities regulations, whilst the IUCN stresses the relevance of visitation and sustainable tourism in protected areas planning and management (Eagles et al. 2002).

Combining ecological conservation and public use requires prioritizing tasks and setting goals (Blicharska et al. 2016) in order not to break the balance between ecological and social needs, particularly when the latter have an impact on the former. Bell et al. (2007) gather a dozen common outdoor activities for the period 1990-2000 including hiking, biking, camping, picnicking, and enjoying nature, and point out their changing popularity. For example, in Scandinavian countries, picking berries and mushrooms was a popular activity in the past, whereas these days it seems to be in decline replaced by snowmobiling (Bell et al. 2007). Visitor's activities and people's behaviour change over time. As social demands, they are variable, dynamic, and heterogeneous: outdoor recreation may be either a solitary or a gregarious activity, and activities in protected areas may be passive such as chilling out, or active such as hiking. Changes in society imply changes in social demands. The Henley Centre (2005) identifies seven social and demographic drivers that translate into public use trends in protected areas: increasing affluent society, wellbeing, reconfiguring age, increased availability of information, social inclusion, risk averse society, and convenience culture. Changes in demographics, life style, and visitor behaviour mean new requests from protected areas and new challenges for their managers (Kati et al. 2014). Visitor monitoring and statistics of public use are key to understanding both people's needs and protected areas' provisions (Leung et al. 2018, Jurado et al. 2019) in order to help decision-making by balancing supply and demand. Traditionally, the management of protected areas has followed a top-down approach (Pellegrino et al. 2016). However, in recent years, a change has been observed and new tools and instruments have appeared to assist managers in their tasks in both a collaborative and participatory manner (Brown and Weber 2011, Engen et al. 2018).

The inclusion of landscape perception and public use in protected areas management is advantageous for biophysical and social reasons, as they have an impact on both areas. People's activities and behaviours have consequences on ecological processes and biodiversity, and also on visitor experience (Hornback and Eagles 1999, Pellegrino et al. 2016). For example, studies on protected beaches have demonstrated that beachgoers get uncomfortable when the beach is overcrowded, and the beach's quality diminishes when too many people gather in a small place (Serrano et al. 2018). Successful managerial practices consider ecological and social knowledge because they help understand nature-culture interactions, particularly those concerning conservation (Blicharska et al. 2016). Planning and management in protected areas are complex tasks, especially if they take into account that the primary reason for sites to be protected is not usually societal-related (EUROPARC 2005, Lauche 2011). Landscape perception and public use are liquid demands in as much as they turn into a service the moment people request them to be (Plieninger et al. 2013, Muñoz et al. 2019). Besides being changeable, user needs may not be well defined or may not be easy to generalise, as many times they are based on perceptions or personal values, preferences, and abilities. A classification of the most common services enjoyed by users 
includes inspirational, religious and spiritual, educational, related to sense of place, culture, heritage and diversity, aesthetic, and recreational, with the last two being the ones requested most by people (Hernández-Morcillo et al. 2013).

Different landscapes provide different services, and users expect distinct landscapes to satisfy their varied demands. Schirpke et al. (2018) studied recreational activities in Italian Natura 2000 sites coming up with different types of users according to their behaviour, revealing the significance of geographical location to explain user activities, and hence their related impact on the environment. Studies in contrasted settings demonstrated that forest-pasture landscapes and landscapes rich in water bodies tend to be particularly sought after as social needs providers (Plieninger et al. 2013, Oteros-Rozas et al. 2018). However, there is more to landscape appraisal than geographical patterns, and this makes it difficult to unequivocally link user preferences to physical elements or landscape features (Tieskens et al. 2018, Chien et al. 2021). Van Zanten et al. (2016) demonstrated that aesthetic preferences are context based in as much as appraised elements are difficult to compare because landscape features are different in scale, the background and foreground contributions alter perceptions, and judgements are made holistically according to geographical and personal contexts. For example, no two beaches are the same, and the same beach is not experienced in the same way in winter or in summer, if visited on your own or with others, if used for sunbathing or for fishing, if surrounded by forests or by summer apartments. The significance of context is at the core of landscape perception, and it relates to holism and chorology as a way of understanding reality. In landscape appraisal that means that landscapes have relative values as their significance varies according to their location, and that landscape features are interdependent on other surrounding features, as the latter interfere mutually when making judgements (Antrop 2000). Besides complex spatial relationships, context approach also requires social assessment because landscape meaning varies with individuals and social groups, and although user preferences exist, they are not linear or unambiguous (Tieskens et al. 2018). Being spatial and social context-based, land- scape appraisal is hardly translatable to other areas, therefore landscape perceived significance and subsequent value needs to be tackled by individual approaches (UK NEA 2014).

Recreational activities contribute significantly to public use in protected areas, to the extent that most of the facilities that protected areas offer are in some way related to recreation (EUROPARC 2005, Bell et al. 2007). Romagosa et al. (2015) explored the link between visitation, recreation, well-being, and protected areas, and pointed out that restorative environments help improve mental and physical health. Public health and environmental agencies ought to work together for the sake of people's well-being, cooperating in a pool of areas including personal recovery and development, exercising, social contact, and inclusion. Protected areas offer an ideal setting for these kinds of activities as they usually provide easy access and appropriate infrastructure (Eagles et al. 2002). Furthermore, research has demonstrated that there is a positive correlation between biodiversity and self-reported benefits of outdoors visitation (Carrus et al. 2015). Besides relaxation, recreational activities usually materialize in a vast array of sports and physical activities that translate into different types of users with varying motivations: behaviour, visitation satisfaction and environmental impact (Farías-Torbidoni 2011, Farías-Torbidoni et al. 2020). Excess visitation occurs when too many users meet together. Crowdedness figures are variable and subjective but even if temporal, congestion may pose a problem, both from the social and environmental point of view, and it needs to be continually reviewed (Serrano et al. 2018). Examples of management related to visitation include the assessment of use along paths, the use of informal trails, inappropriate litter disposal, locating conflicts between users, encroachment on access-regulated sites, zoning crowding perception, and visitor satisfaction rates (Bell et al. 2007, Kuba et al. 2018, Wolf et al. 2018, Jurado et al. 2019).

Visitor opinion is useful for sensing people's behaviour, assessing public use, and addressing recreational opportunities (Hernández-Morcillo et al. 2013, Schirpke et al. 2018). PPGIS refer to Geographic Information Systems (GIS) procedures and the technology used in geo-collaborative processes. The ESRI 
GIS dictionary highlights its role in decision-making and planning, and draws attention to the breadth of the term, since it can include either the design of GIS tools for making data accessible, or the knowledge acquired through PPGIS-based procedures (ESRI 2021). The benefits of using PPGIS tools in protected areas include understanding spatial and temporal dynamics, benefiting from user knowledge, incorporating local people's values, increasing societal engagement, and overcoming top-down approaches (Plieninger et al. 2013, Kati et al. 2014, Blicharska et al. 2016). Several compilations on PPGIS have been published to date (McLain et al. 2013, Corbett et al. 2016, Kahila-Tani et al. 2019), and research has been conducted on PPGIS and protected areas, mainly focusing on planning, visitor monitoring, and negative impact assessment (Brown and Weber 2011, Levine and Feinholz 2015, Engen et al. 2018). However, Pietilä and Fagerholm (2019) point out that PPGIS tools have been glossed over more by the Academia than by public agencies or protected areas managers, and that there is a lack of experiences incorporating manager perspective. Besides, although social demands have been incorporated into PPGIS tools, their development has focused commonly on visitor behaviour, and usually they have not delved into managerial implications. Therefore, the following question is posed: How landscape perception and public use approached via PPGIS can help protected areas management?

In this paper, we address the inclusion of landscape perception and public use as social demands that deserve special attention in protected areas management. We introduce a Public Participatory Geographic Information System (PPGIS) as a tool for gathering information on the opinions and behaviour of visitors to a protected area, and we demonstrate its benefits in management by providing concrete examples. The study was conducted in 2016 in the Ebro Delta Natural Park, a protected area in northeast Spain, and we describe the managerial actions undertaken throughout the following years once the study was completed. After this introduction, the following section broaches on the main characteristics of the study area, whilst section three expands on the method and the PPGIS questionnaire. Section four discusses the results providing concrete examples on managerial practices and within the frame- work of PPGIS experiences in other protected areas. After that, section five assembles some closing thoughts and points to future research.

\section{Area studied}

The Ebro Delta extends over $330 \mathrm{~km}^{2}$ on the eastern façade of the Iberian Peninsula, it is considered one of the largest wetlands in the Western Mediterranean, and it is protected under several designations due to its natural, ecological, cultural and scenic values (Figure 1).

The area is mainly covered with rice cultures, which occupy nearly $70 \%$ of it, but it is also home to a variety of natural and semi-natural habitats such as fresh-water wetlands, salt marshes, salt meadows, and riverine forests. Habitats listed in Annex I of the Habitats Directive include calcareous fens with Cladium mariscus, fixed coastal dunes with Crucianellion maritimae, and slack dunes. A number of listed and endangered wildlife species breed or overwinter in the Ebro Delta, with waterfowl being particularly noteworthy. Remarkable colonies of Audouin's gull (Ichthyaetus audouinii) and Greater Flamingo (Phoenicopterus roseus) are found in the area. Although rich in natural heritage, the Ebro Delta is a cultural landscape. Rice cultures are supported by a dense network of irrigation canals and ditches, major and minor roads crisscross the area, and several medieval towers, hermitages, traditional cottages, hunting hutches, and other elements appear in various places (Generalitat de Catalunya 2021). Built-up areas account for $3.12 \%$ of the area, and nearly 62,000 inhabitants dwell in it permanently. Population is mostly concentrated in three main settlements, although the number of urban patches totals 13 , including two resorts with a summer floating population of over 1,000 households. The general impression many visitors have is that the Ebro Delta's landscape is rich and of high quality, if dominated by rice cultures (Figure 2).

Due to its natural and cultural heritage, ecological processes, and scenery the Ebro Delta was designated Natural Park in 1983. Since then other programmes have watched over its values including the Natura 2000 Network, the Man and Biosphere 


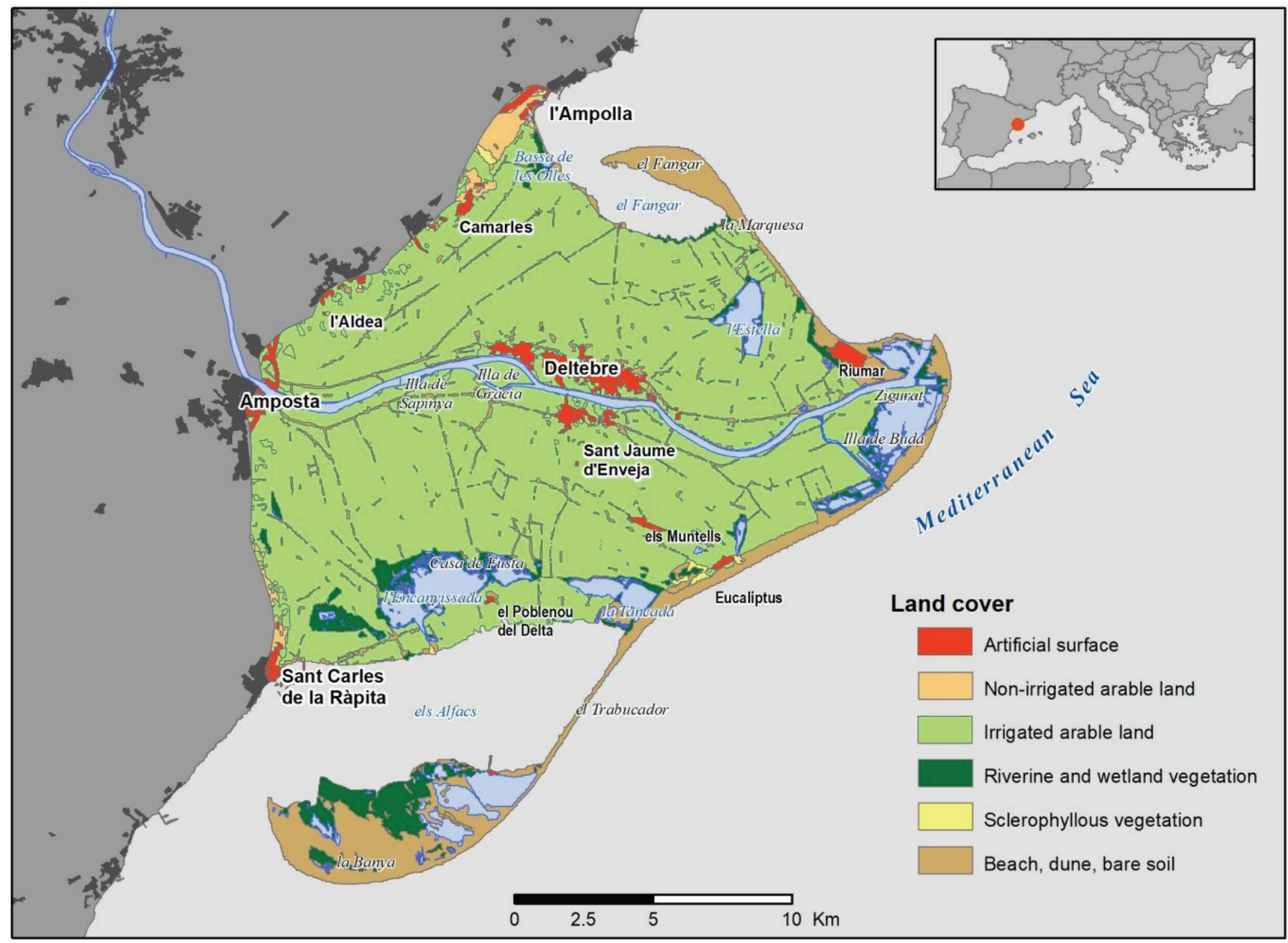

Figure 1. Location of the area studied and main land cover types.

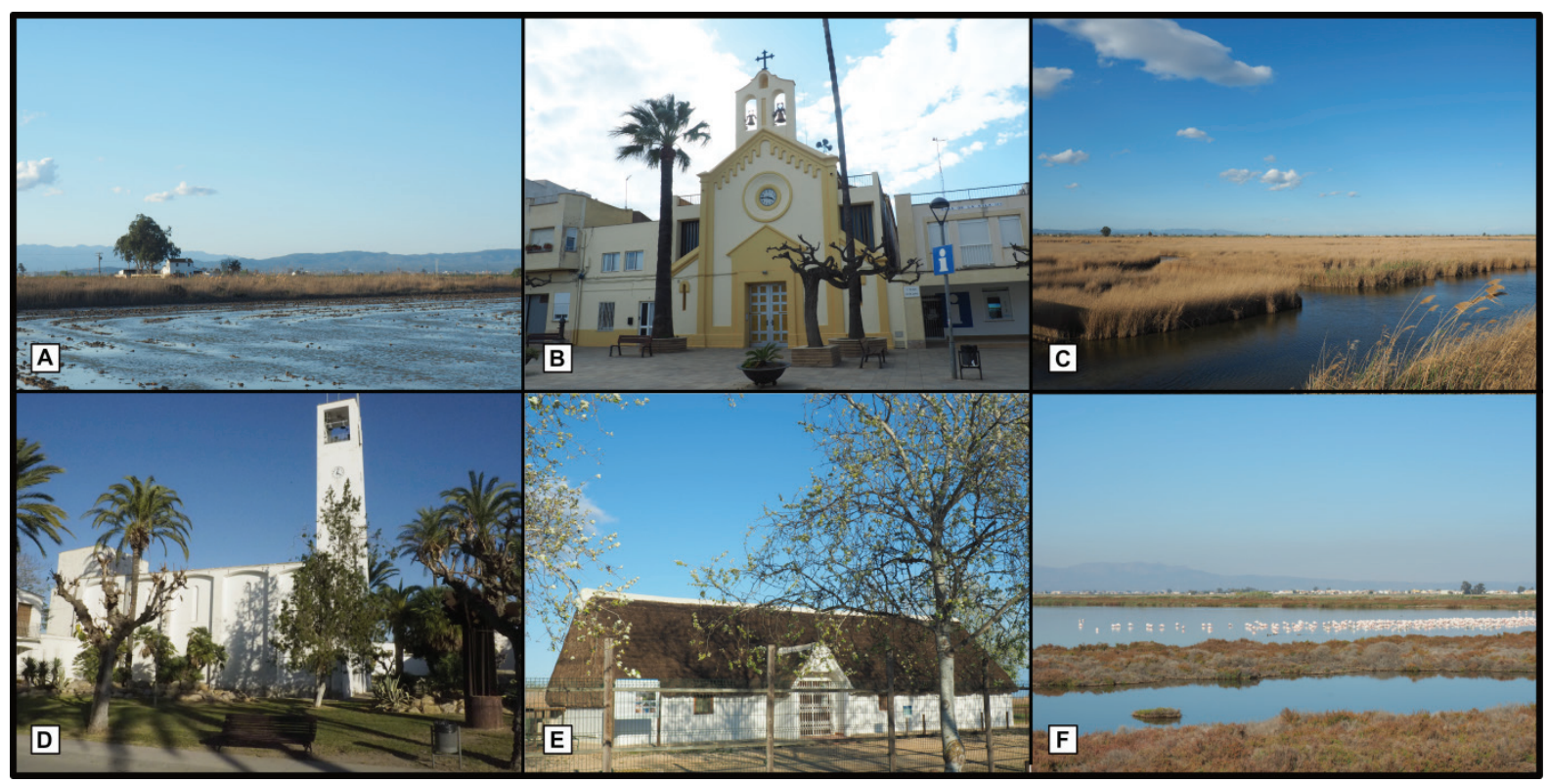

Figure 2. Relevant landscapes and landscape features in the area under study: A: rice culture in winter and traditional cottage; B: urban settlement: Sant Jaume d'Enveja; C: wetland vegetation; D: urban settlement: Poblenou del Delta; E: natural park's facilities in a traditional hut; F: a flock of flamingos in a brackish marsh. 


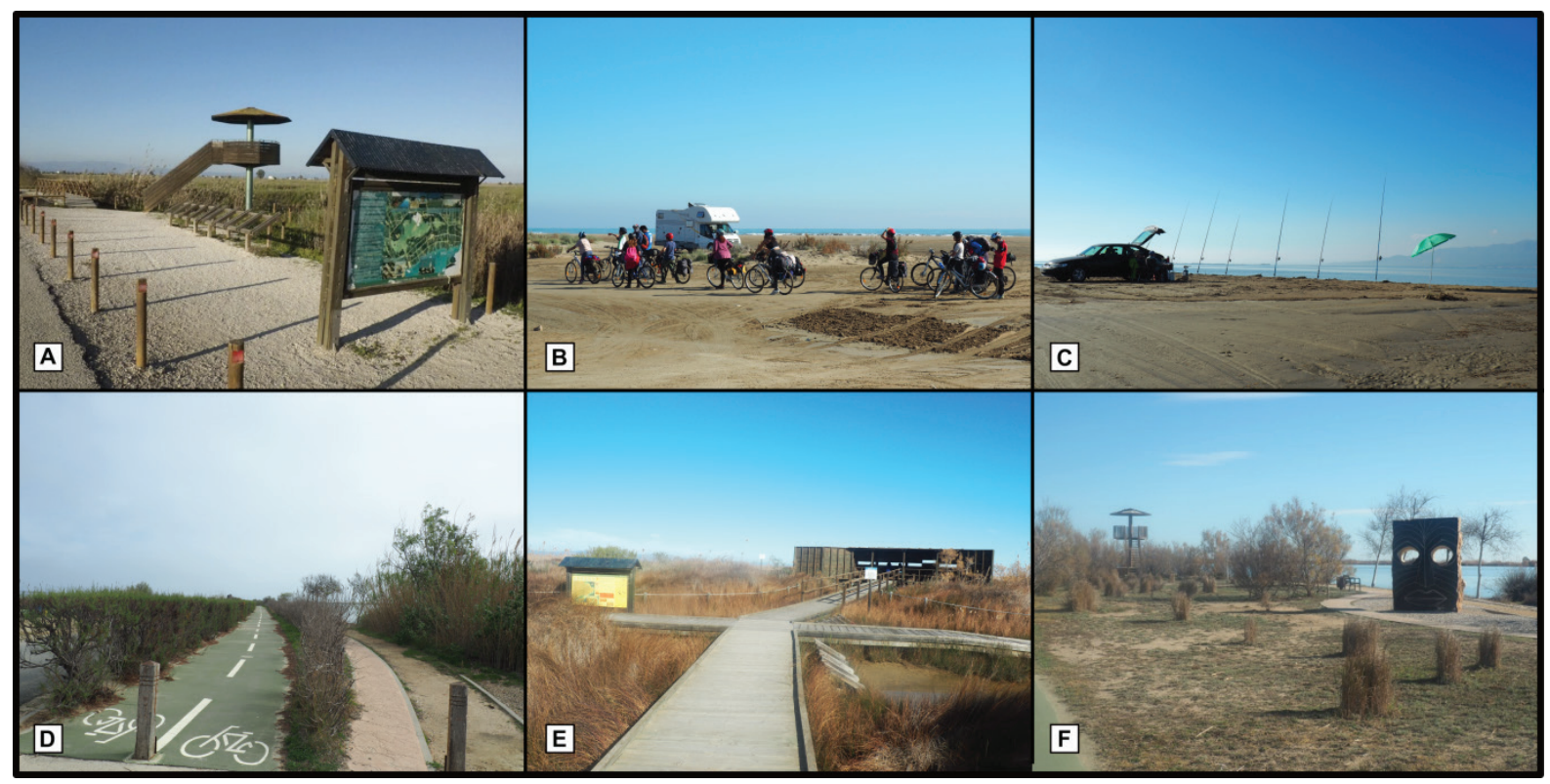

Figure 3. Relevant tourist attractions and leisure activities in the area under study: A: information panel, viewpoint, and bike docking; B: cycling; C: recreational fishing; D: bike path; E: hide for birdwatching; F: leisure area.

programme, and the Ramsar Convention. The area is also included in a landscape catalogue aimed at providing guidelines in regional planning (Generalitat de Catalunya 2010), and the private foundation Fundació Catalunya-La Pedrera, develops environmental education projects on birdwatching, traditional fishing and salt harvesting techniques. Over 150,000 people visit the area each year (Generalitat de Catalunya 2021). Visitors are pretty diverse and respond to different tourist profiles, with the most common being the "ecotourist" (44.6\%) followed by "beach tourists" (39.3\%). The former tends to spend 2-4 days in the area, staying at hotels, campsites or local B\&B; the latter sojourns for 5-7 days if staying in apartments, or for over a week if staying in second homes (Anton-Clavé et al. 2007). International visitors come from a variety of countries including the United Kingdom, France and Germany. However, the most numerous group comes from other regions of Spain, with most of them coming from the area of Barcelona (some $175 \mathrm{~km}$ to the north-east). The main tourist attractions are nature based and include wildlife observation, outdoors activities, beaching, and sampling the local cuisine (Figure 3 ).

The Park offers a variety of amenities including two visitor centres, one eco-museum, a number of hides for birdwatching, picnic areas, vantage points, and information panels. A network of ten official trails designed to be done on foot, bike or horseback passes over $220 \mathrm{~km}$ and helps the visitor discover the area. Park authorities promote sustainable visitation and environmentally friendly activities, and are concerned about visitor behaviour and negative impacts such as overcrowding or people encroaching on access-restricted reserves (Jurado et al. 2019). A management plan is currently in draft, and a set of conservation objectives and guidelines has already been agreed (Generalitat de Catalunya 2021). Local and regional authorities are also keen on low impact activities, and nature based tourist attractions are generally regarded as a source of tourism and economic revenue. There is also a general feeling that the protected area status and the respect for the environment bring some sort of added value to local resources. For example, traditional fishing methods are encouraged and well regarded, and rice grown in the Ebro Delta enjoys its own appellation of origin.

\section{Materials and methods}

A PPGIS questionnaire was designed in purpose together with managers of the Natural Park. Cooperation between the Ebro Delta Natural Park and University Rovira i Virgili appeared as a result of a three year's collaboration programme aimed at 
understanding and assessing public use by means of Geographic Information Technologies. The main output of this programme was a set of measures, actions, and guidelines on public use; besides the PPGIS questionnaire presented hereby, other outputs of this programme included assessing public use via GNSS technology, and approaching landscape perception through social media photographs. The questionnaire was conceived to be answered on line, used Google Maps' interface, and it was available for one year.

\subsection{Design of the questionnaire}

The PPGIS procedure was conceived as a spatial online questionnaire (Brown and Weber 2011) aimed at gathering information on both a geographical and thematic basis. Google Maps was used as a cartographic reference (Bearman and Appleton 2012) and the questionnaire was based on Google Maps' application programming interface (API). This API runs on Hypertext Markup Language (HTML) so it is easily embedded into a webpage as a mashup. The HTML code was modified with Notepad++ using JAVASCRIPT. Google Forms was used to collect the answers, which were stored on an online spreadsheet and automatically classified. Special attention was paid to spatial information (latitude and longitude coordinates), which was used to georeference the output provided by the participants. Finally, the questionnaire was hosted online via Dropbox and Hostinger. The questionnaire was designed together with managers of the park, and was intended to be easy and understandable for the participants. The rationale behind the spatial enquiry was that respondents would select an item describing the landscape, facilities, or leisure activities, drag it onto the map, and locate it in the desired location by rating it (Figure 4).

The heading of the questionnaire gave information about the purpose of the study, the project in which it was framed, the PPGIS, and confidentiality of data. Input was analysed anonymously and aggregated in such way that it was not possible to identify preferences for a given participant. Language was used in an inclusive manner, and it was sensitive to cultural, racial and gender contents. The layout of the questionnaire was a single column for the first section and two columns for the next sections. The column on the left showed a list of items to be selected, rated and placed on a map. The column on the right showed a map of the area under study. A box gave brief and clear instructions on how to use and

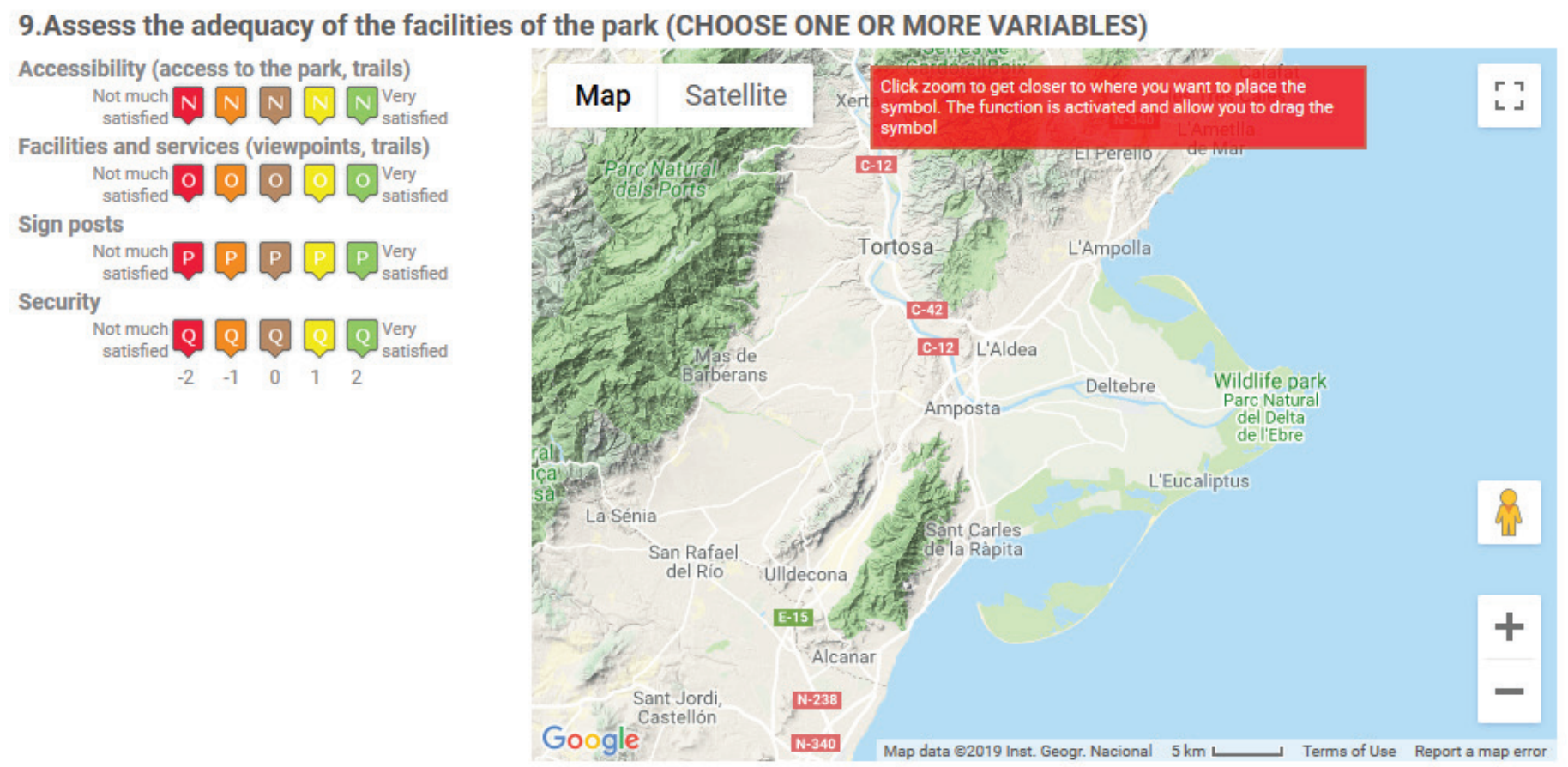

Figure 4. Image of the third section of the questionnaire, where respondents were asked to rate items about facilities in the Natural Park. 
fill in the questionnaire. The items had five possible responses ranging from "very negative" to "very positive": "very negative/positive", "fairly negative/ positive", and "neutral". Each response was associated to colours varying within red to green so that they could be used intuitively. A pop-up window appeared when the cursor was scrolled onto each item to provide further information about its meaning. Each item was coded with a letter to make it easy to classify the results and the score selected by the respondent. This procedure helped standardize and classify the results (Brown and Weber 2011). The respondents did not need to answer all the items or to use all the possible scores but they were encouraged to answer as many of the items as they wished. A version of the questionnaire, which is only available for consultation in the context of this paper, can be accessed at: http://interactivemaps.esy.es/web/ index de en.html, and a pdf. copy is appended as a complementary file.

To ensure accuracy, respondents were asked to zoom in on the map at a graphic scale of at least $1 \mathrm{~km}$ so that the locations they recorded could be considered reliable. Once the respondents had zoomed in, all they had to do was place their chosen score in the appropriate place. When they did so, a window appeared asking for further information, such as the name of the site or any other observation the respondent wished to report. The respondents were encouraged to provide any extra information they wished but were not obliged to do so. There was no maximum number of items to record. However, for the questionnaire to be considered valid, at least one item was required. As is common with Google Maps API, the respondents were able to visualize the map as a topographic or satellite layout and to choose shaded relief and place name labels. The main aim was to help participants get their bearings in the area under study (Levine and Feinholz 2015).

A quality check was conducted to ensure the quality of the data. The questionnaires were accepted if they satisfied the three following conditions: at least one spatial-based question was answered; the spatial answers referred to the area under study; the answers were spatially coherent, i.e. they did not report misleading locations and were not redundant.
Dissemination of the questionnaire was the key to reaching the maximum number of respondents (Bearman and Appleton 2012, Czepkiewicz et al. 2016). Since the questionnaire was designed to be hosted and answered online, we thought that the easiest way to attract participants was also through an online medium. Social media channels were used, including Twitter and Facebook Ebro Delta Natural Park accounts. The questionnaire was available from August 2015 to July 2016. Participation was encouraged through the implementation of successive calls using a variety of social media, email distribution lists, press releases, leaflets and posters. The main target was adult population, either residents or visitors, but no restrictions were imposed on respondents under 18 years of age. In order to engage the highest number of participants, the questionnaire was offered in four languages: Catalan, Spanish, French and English, being French and English specially intended for international visitors.

We encouraged visitors to participate in the questionnaire by raffling a tablet (SX 100 Black Woxter valued $€ 150$ ), which was a popular item at the time the questionnaire was conducted. The participants were asked to provide their email address so that they could be contacted if they won the prize. A brief explanation was added to this item clearly stating that the respondents did not need to provide their email address if they did not wish to take part in the raffle.

\subsection{Sections of the questionnaire}

The first section of the questionnaire included general items aimed at characterizing the respondents. The participants were asked about their country of residence, place of residence, age and profession; the distinction between country and place of residence was intended to determine differences between local visitors and non-local visitors and to test local knowledge (Levine and Feinholz 2015). For this set of questions, we used open questions allowing for up to 22 characters. Two more questions asked respondents about the time since their last visit and the frequency of their visits; the answers to these questions were multiple choice in order to enable a standardized questionnaire (Brown and Fagerholm 2015). 
Table 1. Bipolar pairs of adjectives used to assess landscape characteristics and experience.

\begin{tabular}{|l|c|c|c|c|}
\hline & \multicolumn{3}{|c|}{ Bipolar pair } \\
\hline $\begin{array}{l}\text { Landscape characteris- } \\
\text { tics }\end{array}$ & Natural-Artificial & Attractive-Repulsive & Productive-Unproductive & Clean-Dirty \\
\hline Landscape experience & Quiet-Crowded & Interesting-Boring & Silent-Noisy & Neat-Neglected \\
\hline
\end{tabular}

The second section of the questionnaire was the first one with spatial content. It comprised eight items that gathered information about landscape perception. Landscape perception was assessed by the semantic differential method (Osgood et al. 1957, Perovic and Folic 2012), which directs attention to the landscape as a whole and makes it easier to understand it in a comprehensive way. The semantic differential method has roots in Gestalt psychology and is based on bipolar pairs of adjectives that describe and characterize landscape perception. Eight pairs of bipolar adjectives were selected. Four of these pairs focused on landscape characteristics and four focused on perceived experience (Perovic and Folic 2012). The eight pairs of bipolar adjectives are shown in Table 1.
The third section of the questionnaire concerned facilities related to public use. It was made up of four items: accessibility, facilities and services, signposting, and safety and security. This list embraces the most familiar items on public use in protected areas. Though it is not comprehensive, it is fairly complete (Figure 4).

The fourth section of the questionnaire focused on leisure activities in relation to public use and was made up of nine items, including one open category. These items took into account the reality of the area under study (Generalitat de Catalunya 2021). The list was comprehensive and included the most common outdoor (e.g. taking photographs) and indoor (e.g. sampling the local cuisine) activities recorded by the

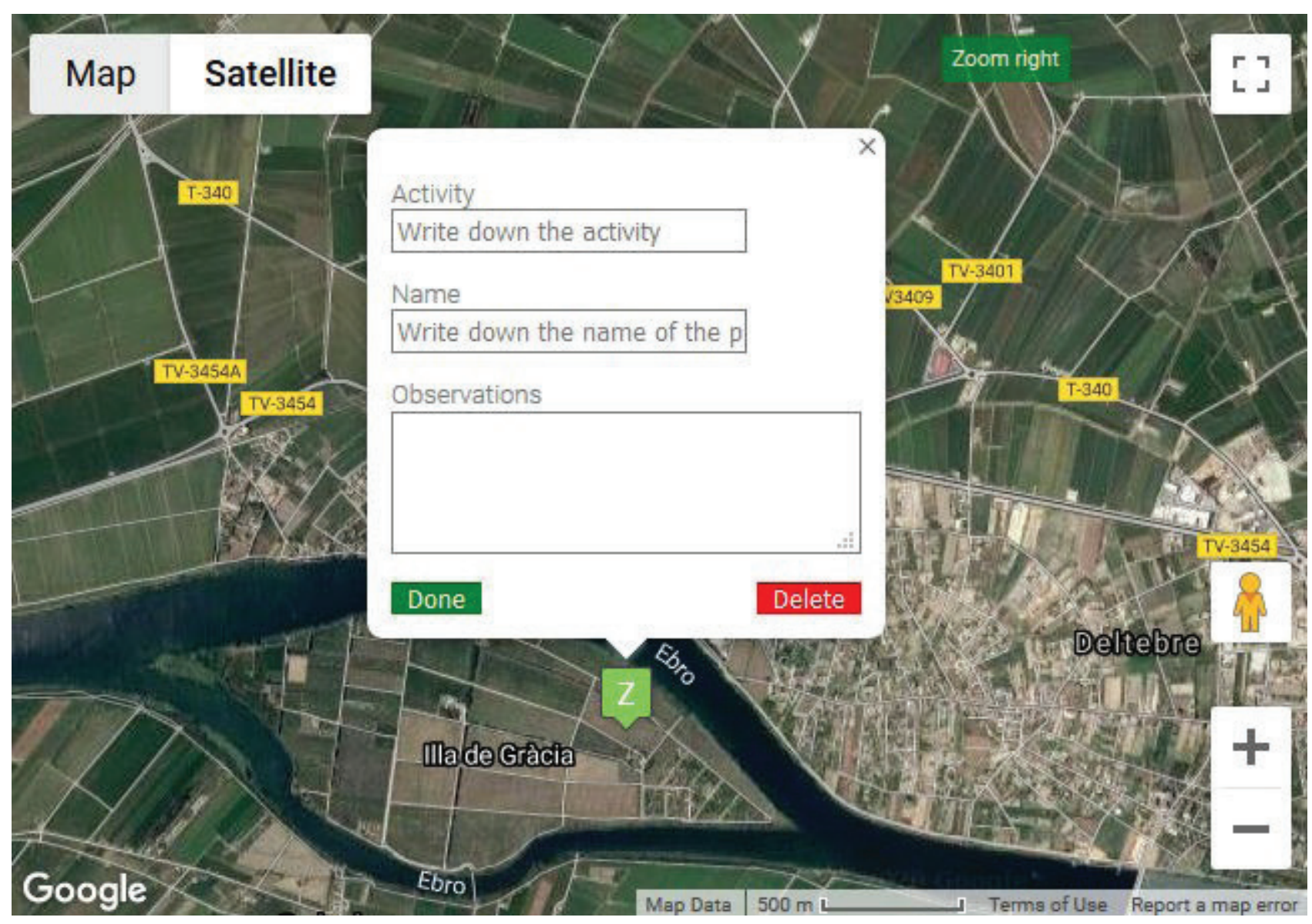

Figure 5. Google Maps API and the pop-up window designed for the participants to provide further information. 
The leisure activities considered were: going to the beach, chilling out, bird watching and enjoying the flora and wildlife, cycling, taking boat trips along the Ebro River, taking photographs, walking, rambling and hiking, and sampling the local cuisine. A final item ('other activities') was included so that the respondents could mention any other activity not included above. A pop-up window was also available when placing scores so respondents were able to expand their input by means of comments (Figure 5).

\section{Results}

A total of 276 questionnaires were received. After applying the above mentioned quality filters, a final number of 204 questionnaires were accepted for the study, which means that $75.73 \%$ of them were valid. Overall, 3,969 valid georeferenced opinions were provided. The number of inputs per respondent was varied: the average was 11.65 opinions, however, the most common number (mode) was 1 , which was also the minimum, whereas the maximum was 119 opinions. The interquartile range was of 15 opinions (Q1 was 2 and Q3 was 17), and the number of obser- vations above Q3 + 1.5 IQR (39.5) was 10. The population was not normally distributed $(\mu=6, \sigma=16.39$ ).

An indirect analysis showed that $55 \%$ of the respondents were women and $37 \%$ were men; $8 \%$ of the respondents were not genre-identified. The respondent mean age was 27.26 years, being the youngest respondent 15 years old and the oldest 55 . Respondents under 35 meant four fifths (81\%) of all the input: $27.2 \%$ of respondents were $20-25$ years old, $19.9 \%$ were $25-30$ years old, $16.2 \%$ were 30 35 years old, and $12.8 \%$ were $35-40$ years old; few participants were aged over 40 and none was aged over 59 . Over four fifths (88\%) of the respondents were not local people. Most of the non-locals were Spaniards but there were also respondents from the United Kingdom, France, and other European countries.

Spatial analysis shows that almost all the feedback fell within the studied area: less than $3 \%$ of the georeferenced opinions were placed outside de Ebro Delta, while nine opinions were deliberately placed in the sea but not far from the coastline. Over $87 \%$ of the opinions identified a place within $2 \mathrm{~km}$ from the shoreline. The most reported site was the mouth of the Ebro River, which received $37.97 \%$ of all feed-
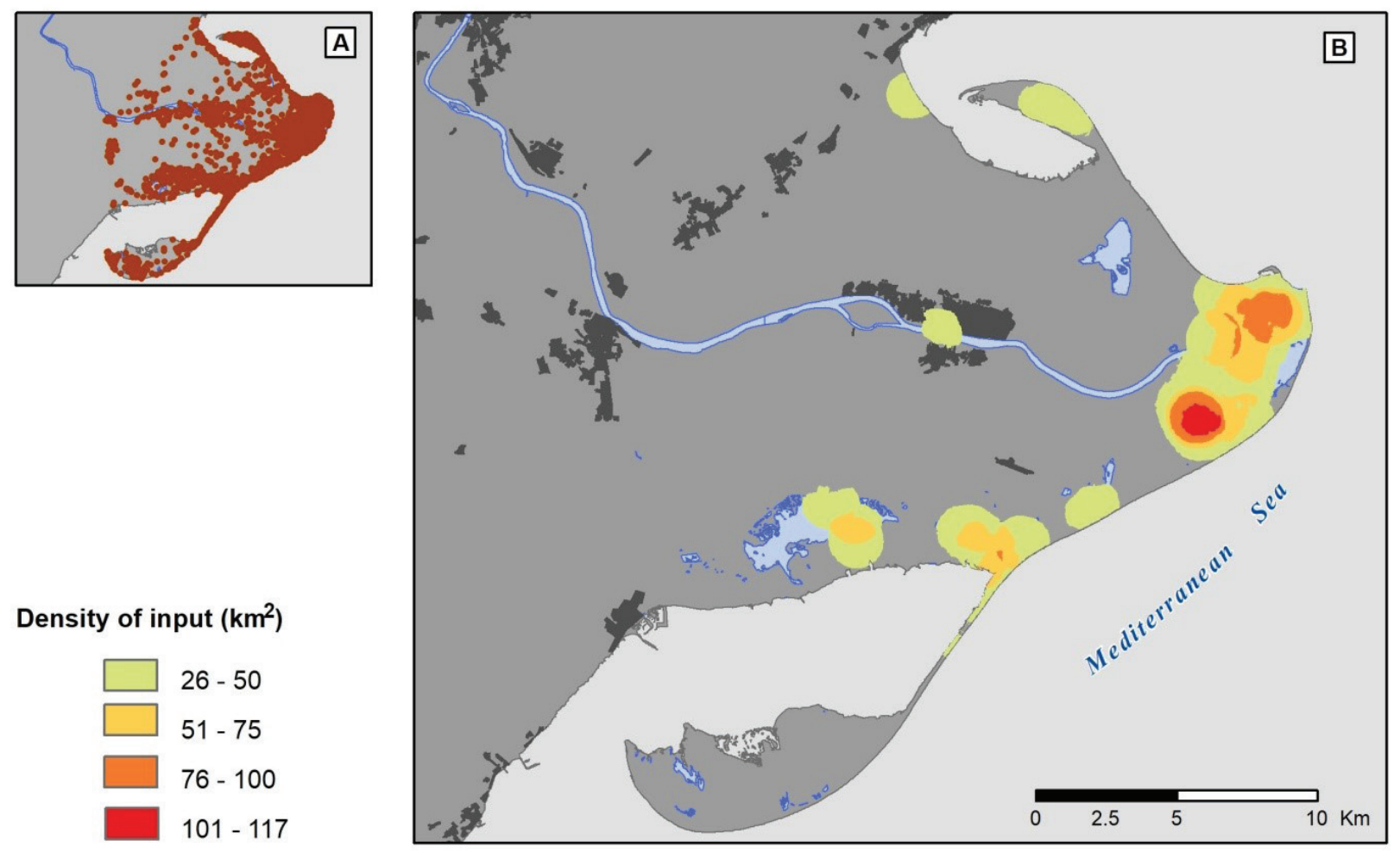

Density of input $\left(\mathrm{km}^{2}\right)$

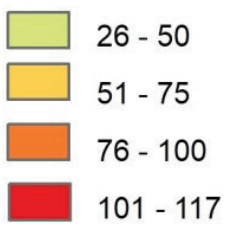

Figure 6. Respondent's opinions: A: georeferenced opinions $(\mathrm{n}=3,969) ; \mathrm{B}$ : density (opinions $\left./ \mathrm{km}^{2}\right)$. 
back; clusters of opinions also appeared in protected areas, tourist attractions, and landmarks. The central Delta area attracted fewer opinions than the margins, though towns received more feedback than the countryside. The spatial distribution of the opinions correlated with the most popular places (Figure 6). However, there was no evident link between number or density of opinions and gates of access to the park, neither main roads. When car parks were in the proximity of tourist attractions, opinions tended to concentrate on the attraction itself; the mouth of the Ebro River is a case in point.

Respondents provided heterogeneous input on the questions asked. Some respondents completed all sections, while others completed only one or two. In the same vein, some respondents gave input for all items per section whilst others only for a few of them. Overall, the items that attracted most answers were those related to landscape perception and recreational activities (Figure 7).

Users' opinion on landscape focused on the naturalness of the site and its aesthetic rating, as the bipolar pairs with more responses refer to "natural-artificial" and "attractive-repulsive" (Figure 7). Users perceived the Ebro Delta landscape mainly positively, with fairly positive judgments, which were the most prevalent; conversely very negative opinions were rare and spatially concentrated in small pockets. Users considered the location as productive, interesting and attractive, for the most part quiet and peaceful, although dirty in some parts. Concerning each item, $62.19 \%$ of the inputs considered the location as "very natural", 70.39\% as "very interesting", and $64.89 \%$ as "very quiet", whereas $16.67 \%$ of the judgements referred "very dirty" locations, and $11.41 \%$ "very neglected".

Concerning public use, "accessibility" and "facilities and services" were the items that attracted more attention (Figure 7). Facilities and services received good scores ( $49.81 \%$ of the users rated them as "very positive") throughout the Ebro Delta, and only a few bad scores appeared in isolated places or natural reserves. $50.73 \%$ of the respondents considered the accessibility to or within the area as "very positive"; however, related item signposting received lower scores $(33.1 \%$ of the respondents rated it as "quite positive" and $28.16 \%$ "positive"). Finally, judgements on safety and security motivated the lowest interac-
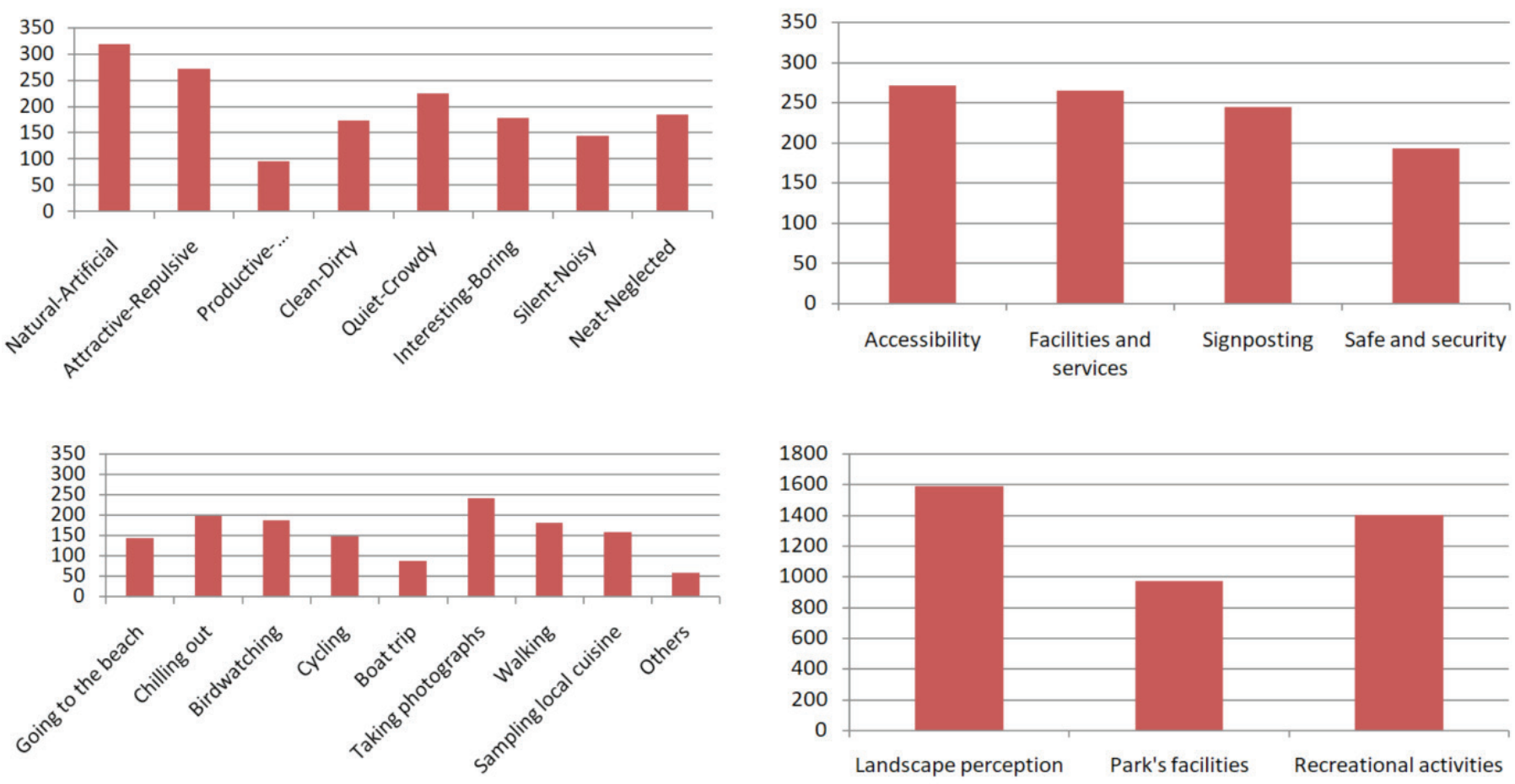

Figure 7. Number of responses per item. From left to right and top to bottom: number of responses per bipolar pair on landscape perception, number of responses per item on facilities, and number of responses per item on recreational activities. The final bar graph summarises total number of input given by respondents. 
tion, although showed medium-to-high satisfaction scores as $45.1 \%$ of the users georeferenced "very positive" and $24.87 \%$ "quite positive" opinions.

Respondents showed high satisfaction scores for all leisure activities. The most common reported activities were taking photographs (6.1\%), walking (4.5\%) and sampling the local cuisine (3.98\%) (Figure 7). The highest scores were given to chilling out (4.7 out of 5), and going to the beach, bird watching and cycling (all of them 4.5 out of 5).

\section{Discussion}

This study gathered information on public use and landscape perception from visitors to the Ebro Delta. A final number of 204 valid questionnaires and 3,969 georeferenced opinions was collected providing useful information on park management and the interest of PPGIS as a management tool in protected areas.

\section{1. Useful information for landscape and public use management}

The respondents to the PPGIS questionnaire had the opportunity to express their opinions about the landscape, their visit, its characteristics, and related experience. Almost all the visitors were keen on natural and attractive landscapes and showed a clear preference for clean and silent landscapes. This is relevant in management because, besides producing georeferenced information, it also provides managers with first-hand knowledge about what visitors appreciate from landscape, regardless of its geographical configuration, land cover type or physical features. Practices willing to improve user satisfaction know that measures should focus on landscapes sensed as artificial or noisy, and on reducing their negative impact or introducing compensatory measures.

By overlaying the opinions given by users on to a topographic map, managers had clear notion of which spots were perceived as more artificial or noisy, and therefore they had information to conduct appropriate measures to address negative perceptions, or ask relevant bodies to do so. An instance of managerial action conducted to improve user satisfaction is given by an intervention undertaken to reduce negative impact in the departure quay for the river cruisers. This spot was negatively regarded, mainly because of being sensed noisy and crowded, as souvenir stalls, restaurants, parking areas and boats converge in a reduced area. In order to decongest the place and help people to get to know the area, a promenade along the river was built linking the quay to a vantage point with a singular design, and placing information panels and photogenic sculptures along the promenade (Figure 3, photograph F). Another instance of managerial action is provided by beaches and popular spots that users considered dirty and, therefore, mapped negatively. This provided spatial evidence to the managers to claim their cleaning to local councils, which are the bodies responsible for removing litter and keeping sites clean. A related example refers to urban interventionism: a large number of respondents sensed landscapes around tourist resorts as artificial and repulsive, and scored them negatively. This provided the managers with evidence to ask for landscape integration measures on urban fronts and to include relevant measures in urban plans.

Table 2. Main issues raised by the PPGIS questionnaire and their management actions.

\begin{tabular}{|l|c|}
\hline Problem noticed & Management action \\
\hline Areas considered dirty by users & Clean and maintain beaches and popular spots. \\
\hline Places with bad signposting or lack of it & $\begin{array}{c}\text { Construction of appropriate infrastructure for birdwatching. } \\
\text { Improvement of wildlife management. }\end{array}$ \\
\hline Birdwatcher gatherings and location of wildlife hides & $\begin{array}{c}\text { Conduct stricter practices to avoid people encroaching sensi- } \\
\text { tive areas. Implement relevant regulations. }\end{array}$ \\
\hline $\begin{array}{l}\text { Inputs in natural reserves where human access is prohibited } \\
\text { or restricted }\end{array}$ & $\begin{array}{c}\text { Assessment of whether or not new car parks are advisable. } \\
\text { Restriction of motorised access to sensitive places. }\end{array}$ \\
\hline $\begin{array}{l}\text { Overcrowded accesses to the beaches and uncontrolled park- } \\
\text { ing in ditches and undesignated areas }\end{array}$ & \multicolumn{2}{|l}{} \\
\hline
\end{tabular}


Scores on signposting are noticeably lower than on any other item, and that helped managers concentrate their efforts on what users sensed as priority. For example, by locating the spots where respondents flagged signposting problems, managers were able to erect appropriate markers, or claim the competent authority to do so.

Numerous respondents reported birdwatching as a leisure activity. Here managers found a useful tool for locating hides in places sought after by birdwatchers, and for creating new wildlife hides in locations that do not disturb waterfowl.

A large number of inputs expressed by participants has been authoritative in management and decision-making. Through the PPGIS questionnaire, managers of the Ebro Delta have found an instrumental tool based on experiential knowledge that has been used to address a variety of problems, which would have been difficult to detect without people's participation. Table 2 shows a set of issues and management actions already undertaken thanks to people's participation in the PPGIS questionnaire.

Potential applications of the input given by respondents include detection of conflictive areas, management of sensitive spots, and optimisation of resources. Scores on facilities and services generally speaking are very good. However, if a cluster of lower scores appears in a given place managers have a warning of a potential conflict. For example, on some beaches, users point out problems with finding appropriate parking lots, which may suggest a need to increase car park areas in order to improve visitor's experience. However, a temporal analysis of negative scores reveals that most of the negative input concentrates around Easter time and the peak of summer, being positive the rest of the year. This provides useful information for sensitive decision-making as managers have information for conducting a cost-benefit assessment and judging whether the measures needed are worth the investment they require. A case in point is provided by Schirpke et al. (2018), which studies recreational activities in protected areas, noticing that many visitation issues have temporal behaviour and hence their impact is punctual. Scores on accessibility are pretty good, in general terms. However, some low marks appear near some reserves where human access is regulated. Here managers have evidence of interest in visiting certain places and, if needed, controlled tours in small groups might be arranged ensuring minimum disturbance to the environment. This is particularly relevant because guided visitation may help put an end to people encroaching on reserves, improve the general knowledge users acquire during their visit, and favour local engagement in conservation. For example, Illa de Buda is a reserve on the mouth of the Ebro River that used to be a privately owned estate. When the site was transferred to public ownership some controlled, guided visits were offered to allow the general public to access the site's values. Albeit controversial, this sort of measure may also constitute a source of income for many protected areas, which usually do not have enough financial autonomy (Pellegrino et al. 2016).

Many visitors enjoy taking photographs during their stay. Managers can use this information to promote discovery trails with scenic views, or to point out main vantage points to users attending the information centre. A suggested managerial practice is to cross popular areas with photographers and popular areas with birdwatchers so as to locate potential critical spots. Managers can also correlate low satisfaction scores in birdwatching with hides, and conduct relevant actions to improve user's satisfaction, for example repairing damaged hides or replacing information panels that have been vandalised. In the Ebro Delta, cycling is a popular activity with users. Managers would find it useful to promote cycle paths as a way of improving user satisfaction among sport-user types. In the same vein, passive-type leisure activities, such as going to the beach or sampling the local cuisine, can be promoted together as they are common to the same tourist profile (Anton-Clavé et al. 2007) and it may mean avoiding unnecessary movements within the park.

Another potential benefit lies in overlaying landscape judgements on to habitat maps in order to pinpoint which habitats are visited and praised the most and, therefore, prevalent in visitor experiences. Research demonstrated that aesthetics is a common social demand (Hernández-Morcillo et al. 2013), and landscapes with aesthetic values provide varying social requirements and therefore raise different in- 
terests and attract assorted types of users (UK NEA 2014, Chien et al. 2021). Managers can detect which settings are more popular and which activities users do, and therefore promote likewise activities in similar settings in order to decongest crowded sites or avoid pressure on the environment. For example, slack dunes tend to be aesthetically sought after by visitors, and managers can suggest different discovery trails in order to ease pressure on popular spots.

\subsection{PPGIS as (participatory) management tool in protected areas}

PPGIS questionnaires provide information that can be used in protected areas management. As shown above, visitor opinions may translate into varying actions aimed at bridging the gap between conservation and social needs, while the input on landscape preferences, public use and recreation may improve biodiversity, ecological processes, and visitor experience.

Input gathered via PPGIS is useful because it provides detailed georeferenced answers, as users have to position their judgements on a map. In many cases, the PPGIS interface calls for the users to zoom in to ensure accuracy. In the Ebro Delta experience, users had to zoom in at least on a graphic scale of $1 \mathrm{~km}$ on the Google Maps layout. Such an accurate scale makes the questionnaire valuable when overlaying people's input on existing spatial information layers such as discovery trails, habitats or reserves boundaries. As Kahila-Tani et al. (2019) pointed out, PPGIS data can be integrated into broader information contexts, therefore providing strong assets when working with public participation. It is also known that spatial knowledge and geographic familiarity with local places is generally higher than the levels existing at less accurate spatial levels, and that this fact affects PPGIS characteristics (Huck et al. 2014, Czepkiewicz et al. 2016). Many studies stressed the need for societal support in conservation (Eagles et al. 2002, Bell et al. 2007, Kati et al. 2014, Blicharska et al. 2016). Case studies (Carver et al. 2001) demonstrated that it is easier to engage participants when studies are carried out on a local scale, and that public response is higher when the local community feels involved. Besides societal engagement, PPGIS has also proved beneficial in gathering local knowledge, considered non-expert opinion, working on a place-based basis and adopting a bottom-up approach (Huck et al. 2014, Corbett et al. 2016, Pellegrino et al. 2016). Bearman and Appleton (2012) pointed out that the PPGIS impact is determined by the utility of its applications and related benefit. Despite the potential benefits of PPGIS, some studies indicate that this kind of data is not yet widely used in planning, and its integration in decision support is still embryonic (Brown and Fagerholm 2015, Pietilä and Fagerholm 2019).

The reason why PPGIS practices are not widely adopted in protected areas management are as varied as numerous, ranging from technical difficulties to excessively rigid working schemes. A common criticism of PPGIS questionnaires is related to its representativeness (Brown and Kyttä 2014). Many times PPGIS participation is voluntary, so respondents do not exemplify the whole universe of visitors to a given site, and results are possibly not being representative or reliable enough. Research shows that PPGIS experiences should be accepted as long as they are able to depict general trends or portray main behaviours, regardless of the number of responses collected. For example, Huck et al. (2014) collected 33 responses in a study on the location of wind farms, Bearman and Appleton (2012), 71 when working on recreational activities in the English countryside, and Engen et al. (2018), 197 and 189 when addressing the management of two protected areas.

The age of participants is a common caveat in PPGIS experiences. Many studies notice a skew towards younger respondents (e.g. Muñoz et al. 2019). A certain disproportion between ages seems to be common in PPGIS questionnaires (Brown and Fagerholm 2015). Possibly there is a "technological gap" since some participants may have difficulty in accessing or understanding digital environments or online geographical information. It can be said that technology is an obstruction and that digital participation is not representative of all citizens. However, Kahila-Tani et al. (2019) notice that technology is just one of the many barriers participants may encounter when answering a PPGIS questionnaire. Another concern is bias and data quality, since respondents may lie or provide false answers even unintentionally (Levine and Feinholz 2015), but paper-based questionnaires 
and indeed any social science study may also have relative reliability (Czepkiewicz et al. 2016). The debate on the reliability of PPGIS data, though important, should not be overstated because one of the main benefits of PPGIS is to provide guidelines for actions rather than a to-do list to follow to the letter.

\section{Final remarks}

In this paper, we presented a PPGIS experience aimed at gathering useful data on landscape and public use for protected areas management. The study was conducted from 2015 to 2016 in the Ebro Delta Natural Park (Spain), it was built on 4,467 georeferenced opinions from 209 valid answers, and depicted a proxy of user behaviours and opinions. It allowed the opportunity for speculation on common trends and to facilitate management considering local and experiential knowledge. The study provided relevant information for management and decision-making, since input expressed by respondents translated into managerial actions implemented over the last few years. First-hand knowledge resulted of particular pertinence to assess public use and preferences, as information came from the same source than originated it and translated into inputs that could not have been achieved via other sources.

Most of the actions undertaken address problems related to cleanness, bad signposting, wildlife hides, restricted areas encroachment, and overcrowding. An upcoming management plan will also benefit from the input gathered by the related PPGIS experience.

The inclusion of PPGIS questionnaires in protected areas management would increase its potential if PPGIS exercises were conducted periodically and visitor needs and opinions were assessed on a permanent and regular basis, as managers would benefit from a continuous and updated flow of user knowledge.

This kind of data source would favour societal engagement and help revert traditional top-down managerial practices, besides assessing social and environmental needs in an up-to-date way. Additionally, it would also contribute to conducting dy- namic management, as social needs are changeable and their approach may result outdated in long-term management plans.

The PPGIS presented in this study could be improved by adding sets of thematic map layers to the reference basemap, such as habitats, types of beaches, birds likely to be watched, or management plans. An interesting feature would be allowing participants to share their own photographs taken during their visit. Besides expressing their opinion and putting their thoughts into words by means of ratings and comments, respondents would be able to share their significant landscapes by posting photographs. This would increase respondent engagement, reinforce visitor input, and help managers understand people's interests. On an online environment, this feature is easy to implement, inexpensive and effortless, and its potential benefits can considerably improve visitor experience and manager tasks. Therefore, a reasonable next step would be to conduct a PPGIS questionnaire using multi-layered maps and including image-data input.

\section{Acknowledgements}

This work was supported by the Spanish Ministry of Science, Innovation and Universities (RESTAURA project, PID 2020-114363GB-I00, and CHORA project, CSO2017-82411-P), AEI/FEDER, EU, and the Department Universities and Research of the Catalan Government (2017SGR22). Joan Borràs assisted designing the online questionnaire, and Xavi Abril provided updated information on management conducted in the Ebro Delta Natural Park.

\section{References}

Anton-Clavé, S., Nel-lo, M. G., \& Orellana, A. 2007. Coastal Tourism in Natural Parks. An Analysis of Demand Profiles and Recreational Uses in Coastal Protected Natural Areas. Turismo \& Desenvolvemento, 7/8, 69-81. DOI:10.34624/rtd. v0i7/8.13729 
Antrop, M., 2000. Background concepts for integrated landscape analysis. Agriculture, Ecosystems and Environment 77, 17-28. DOI:10.1016/S01678809(99)00089-4

Bearman, N., Appleton, K. 2012. Using Google Maps to collect spatial responses in a survey environment. Area44,2, 160-169. DOI:10.1111/ j.1475-4762.2012.01081.x

Bell S., Tyrväinen, L., Sievänen, T., Pröbstl, U., Simpson, M. 2007. Outdoor Recreation and Nature Tourism: A European Perspective. http:// Irlr.landscapeonline.de [Accessed 14 March 2021].

Blicharska, M., Orlikowska, E.H., Roberge, J-M., Grodzinska-Jurczak, M. 2016. Contribution of social science to large scale biodiversity conservation: A review of research about the Natura 2000 network. Biological Conservation 199, 110-122. DOI:10.1016/j.biocon.2016.05.007

Brown, G. Fagerholm, N. 2015. Empirical PPGIS/PGIS mapping of ecosystem services: A review and evaluation. Ecosystem Services 13, 119-133. DOI: 10.1016/j.ecoser.2014.10.007

Brown, G., Kyttä, M. 2014. Key issues and research priorities for public participation GIS (PPGIS): A synthesis based on empirical research. Applied Geography 46, 122-136. DOI:10.1016/j. apgeog.2013.11.004

Brown, G., Weber, D. 2011. Public Participation GIS: A new method for national park planning. Landscape and Urban Planning 102, 1-15. DOI:10.1016/j.landurbplan.2011.03.003

Carrus, G., Scopelliti, M., Lafortezza, R., Colangelo, G., Ferrini, F., Salbitano, F., Agrimi, M., Portoghesi, L., Semenzato, P., Sanesi, G. 2015. Go greener, feel better?. The positive effects of biodiversity on well-being of individuals visiting urban and periurban green areas. Landscape and Urban Planning 134, 221-228. DOI:10.1016/j. landurbplan.2014.10.022

Carver, S., Evans, A., Kingston, R., Turton, I. 2001. Public participation, GIS, and cyberdemocracy: evaluating on-line spatial decision support systems. Environmment and Planning B: Planning and Design 28, 907-921. DOI:10.1068/b2751t
Chien, C.Y-M., Carver, S., Comber, A. 2021. An Exploratory analysis of expert and NonexpertBased Land-scape Aesthetics evaluations: A case study from Wales. Land 10, 1-17. DOI:10.3390/ land 10020192

Corbett, J., Cochrane, L., Gill, M. 2016. Powering Up: Revisiting Participatory GIS and Empowerment. The Cartographic Journal 53, 4, 335-340. DOI:10 $.1080 / 00087041.2016 .1209624$

Czepkiewicz, M., Jankowski, P., Młodkowski, M. 2016. Geo-questionnaires in urban planning: recruitment methods, participant engagement, and data quality. Cartography and Geographic Information Science 44, 551-567. DOI:10.1080/1 5230406.2016.1230520

Eagles, P.F.J., McCool, S.F., Haynes, C. 2002. Sustainable Tourism in Protected Areas: Guidelines for Planning and Management. IUCN, Gland.

Engen, S., Runge, C., Brown, G., Fauchald, P., Nilsen, L., Hausner, V. 2018. Assessing local acceptance of protected area management using public participation GIS (PPGIS). Journal of Nature Conservancy 43, 27-34. DOI:10.1016/j. jnc.2017.12.002

ESRI 2021. ESRI GIS Dictionary. https://support.esri. com/en/other-resources/gis-dictionary/browse/ [Accessed 17 March 2021].

EUROPARC 2005. Manual Sobre Conceptos de uso Público en los Espacios Naturales Protegidos. Fundación González Bernáldez, Madrid.

Farías Torbidoni, E. I. 2011. Managing for Recreational Experience Opportunities: The Case of Hikers in Protected Areas in Catalonia, Spain. Environmental Management 47, 482-496. DOI:10.1007/s00267-010-9606-z

Farías-Torbidoni, E.I., Mas-Alòs, S., Gil-Moreno de Mora, G., Lavega-Burgués, P., Castañer, M., Lorente-Catalán E., Seguí-Urbaneja, J., LacasaClaver, E. 2010. Health and Well-Being in Protected Natural Areas-Visitors' Satisfaction in Three Different Protected Natural Area Categories in Catalonia, Spain. International Journal of Environmental Research and Public Health 17, 1-19. DOI:10.3390/ijerph17186746 
Generalitat de Catalunya 2010. Terres de l'Ebre. Catàleg de paisatge. http://www.catpaisatge.net/ eng/catalegs_presentats_E.php [Accessed 17 March 2021].

Generalitat de Catalunya 2021. Parc Natural del Delta de l'Ebre. http://parcsnaturals.gencat.cat/ ca/delta-ebre [Accessed 17 March 2021].

Henley Centre 2005. Demand for outdoor recreation. A report for Natural England's outdoor recreation strategy. Paper 2: Demand for outdoor recreation - Natural England. http://publications. naturalengland.org.uk [Accessed 11 November 2021].

Hernández-Morcillo, M., Plieninger, T., Bieling, C. 2013. An empirical review of cultural ecosystem service indicators. Ecological Indicators 29, 434444. DOI:10.1016/j.ecolind.2013.01.013

Hornback, K.E., Eagles, P.F.J. 1999. Guidelines for Public Use Measurement and Reporting at Parks and Protected Areas. IUCN, Dordrecht.

Huck, J.J., Whyatt, J.D., Coulton, P. 2014. A PPGIS for capturing imprecise notions of place. Applied Geography 55, 229-237. DOI:10.1016/j. apgeog.2014.09.007

Jurado Rota, J., Pérez Albert, M.Y., Serrano Giné, D. 2019. Visitor monitoring in protected areas: an approach to Natura 2000 sites using Volunteered Geographic Information (VGI). Geografisk Tidsskrift-Danish Journal of Geography 119, 1, 6983. DOI:10.1080/00167223.2019.1573409

Kahila-Tani, M., Kytta, M.,Geertman, S. 2019. Does mapping improve public participation? Exploring the pros and cons of using public participation GIS in urban planning practices. Landscape and Urban Planning 185, 45-55. DOI:10.1016/j. landurbplan.2019.02.019

Kati, V., Hovardas, T., Dieterich, M., Ibisch, P. L., Mihok, B., Selva, N. 2014. The challenge of implementing the European network of protected areas Natura 2000. Conservation Biology 29,1-10. DOI:10.1111/cobi.12366

Kuba, K., Monz, C., Bårdsen, B-J., Hausner, V.H. 2018. Role of site management in influencing visitor use along trails in multiple alpine protected areas in Norway. Journal of Outdoor Recreation and Tourism 22, 1-8. DOI:10.1016/j.jort.2018.02.002.

Levine, A.S., Feinholz, C.L. 2015. Participatory GIS to inform coral reef ecosystem management: Mapping human coastal and ocean uses in Hawaii. Applied Geography 59, 60-69. DOI:10.1016/j. apgeog.2014.12.004

Lausche, B. 2011. Guidelines for Protected Areas Legislation. IUCN, Gland.

Leung, Y.-F., Spenceley, A., Hynegaard, G., Buckley, R. 2018. Tourism and Visitor Management in Protected Areas: Guidelines for Sustainability. IUCN, Gland.

Levine, A.S., Feinholz, C.L. 2015. Participatory GIS to inform coral reef ecosystem management: Mapping human coastal and ocean uses in Hawaii. Applied Geography 59, 60-69. DOI:10.1016/j. apgeog.2014.12.004

McLain, R., Poe, M., Biedenweg, K., Cerveny, L., Besser, D., Blahana, D. 2013. Making Sense of Human Ecology Mapping: An Overview of Approaches to Integrating Socio-Spatial Data into Environmental Planning. Human Ecology 41, pp. 651-665. DOI:10.1007/s10745-013-9573-0

Muñoz, L., Hausner, V., Brown, G., Runge, C., Fauchald, P. 2019. Identifying spatial overlap in the values of locals, domestic and international tourists to protected areas. Tourism Management 71, 259271. DOI:10.1016/j.tourman.2018.07.015

Osgood, C.E.; Suci, G.J., Tannebaum, P. 1957. The measurement of meaning. Oxford, University of Illinois Press.

Oteros-Rozas, E., Martín-López, B., Fagerlhom, N., Bieling, C., Plieninger, T. 2018. Using social media photos to explore the relation between cultural ecosystem services and landscape features across five European sites. Ecological Indicators 94, 7486. DOI:10.1016/j.ecolind.2017.02.009

Pellegrino, D., Schirpke, U., Marino, M. 2016. How to support the effective management of Natura 2000 sites? Journal of Environmental Planning and Management 60, 383-398. DOI:10.1080/096 40568.2016.1159183 
Perovic, S., Folic, N.K. 2012. Visual perception of public open spaces in Niksic. Procedia - Social and Behavioral Sciences 68, 921-933. DOI:10.1016/j. sbspro.2012.12.277

Pietilä, M., Fagerholm, N. 2019. A management perspective to using Public Participation GIS in planning for visitor use in national parks. Journal of Environmental Planning and Management 62, 1133-1148. DOI:10.1080/09640568.2018.147375 7

Plieninger, T., Dijks, S., Oteros-Rozas, E., Bieling, C. 2013. Assessing, mapping, and quantifying cultural ecosystem services at community level. Land Use Policy 33, 18-129. DOI:10.1016/j. landusepol.2012.12.013

Romagosa, F., Eagles, P.F.J., Lemieux, C. 2015. From the inside out to the outside in: Exploring the role of parks and protected areas as providers of human health and well-being. Journal of Outdoor Recreation and Tourism 10, 70-77. DOI:10.1016/j. jort.2015.06.009.

Schirpke, U., Scolozzi, R., Da Re, R., Masiero, M., Pellegrino, D., Marino., D. 2018. Recreational ecosystem services in protected areas: A survey of visitors to Natura 2000 sites in Italy. Journal of Outdoor Recreation and Tourism 21, 39-50. DOI:10.1016/j.jort.2018.01.003

Serrano Giné, D., Pérez Albert, M.Y., Bonfill Cerveró, C. 2018. The DIBA: a dynamic assessment tool for beach quality in protected areas. Scottish Geographical Journal 134, 3-4, 237-256. DOI:10. 1080/14702541.2018.1489557

Tieskens, K., Van Zanten, B., Schulp, C.J.E., Verburg, P.H. 2018. Aesthetic appreciation of the cultural landscape through social media: An analysis of revealed preference in the Dutch river landscape. Landscape and Urban Planning 177, 128-137. DOI:https://doi.org/10.1016/j. landurbplan.2018.05.002

UK National Ecosystem Assessment 2014. The UK National Ecosystem Assessment: Synthesis of the Key Findings. UNEP-WCMC, Cambridge.

Van Zanten, B., Verburg, P.H., Scholte, S.S.K., Tieskens, K.F. 2016. Using choice modeling to map aesthetic values at a landscape scale: Lessons from a Dutch case study. Ecological Economics 130,221-231. DOI:10.1016/j.ecolecon.2016.07.008

Wolf, I.D., Brown, G., Wohlfart, T. 2018. Applying public participation GIS (PPGIS) to inform and manage visitor conflict along multi-use trails. Journal of Sustainable Tourism 26, 470-495. DOI :10.1080/09669582.2017.1360315 